\title{
Monitoring of time and cost variances of schedule using simple earned value method indicators
}

\author{
Daniel Przywara ${ }^{1}$ and Adam Rak ${ }^{2, *}$ \\ 1 Opole University of Technology, Faculty of Civil Engineering and Architecture, Department of Civil \\ Engineering and Construction Processes; d.przywara@po.edu.pl \\ 2 Opole University of Technology, Faculty of Civil Engineering and Architecture, Department of Civil \\ Engineering and Construction Processes; a.rak@po.edu.pl \\ * a.rak@po.edu.pl
}

\begin{abstract}
The Planning and implementation of construction projects are difficult processes and are burdened with many risk elements. The budget spread over time, which is developed on the basis of the schedule, presents the expected distribution of costs throughout the duration of the works, which during the implementation of the project is subject to constant changes resulting from time, cost and organizational factors. Managing construction contracts requires managers to be able to analyze on an ongoing basis the variances of production costs - from the values calculated in the offer cost estimate and assumed in the Budgeted Cost of Work Scheduled. The article attempts to analyze the emerging time and cost deviations using proprietary $\mathrm{T} / \mathrm{S}$ and $\mathrm{T} / \mathrm{C}$ monitoring, based on simple indicators of the EVM method. An example of construction of a multi-family housing development was used to study the variances of planned and incurred costs.
\end{abstract}

Keywords: Earned Value Method - EVM; time variances; cost variances; schedule

\section{Introduction}

The growing number and growing importance of unique, often complex construction projects, results in unflagging interest in project management. Despite the undisputed, more significant than ever, development of effective methods of planning, coordinating and controlling, the increase in the complexity of operating conditions of the enterprise on the market means that, success in project management is not easier. The selection of production control methods depends on many factors - primarily the degree of production repeatability, as well as the degree of details of available data, the details of the records kept, the use of planning documentation, the degree of use of computer techniques and the organizational culture prevailing in the company. Construction production is characterized with significant seasonal fluctuations. They constitute a cycle of repetitive changes, in more or less equal periods of time, with similar intensity. Their identification and inclusion considerably increases the precision of predictions [1,2,3].

Earned Value Method (EVM) is recognized as an advanced method of controlling production ventures, which provides working results in the form of quantitative and qualitative indicators.

The purpose of developing the EVM method was to link the material progress of works and the costs incurred - against the background of planned values. This tool, "introduced" to construction sites, has been effectively implemented and disseminated. Managers managing complex construction contracts use key words to assess the progress of their schedules, fully describing planned and actual turnover, budget and timeliness of implementation. These include simple control indicators of the earned value method, used in the strategic assessment of the condition of the project - when monitoring the progress of works using the indicator method [4,5,6,7]. The EVM method is one of performancebased project management methods and is an effective tool for controlling projects in terms of costs, 
time and scope of works done [8]. It consists of controlling the implementation of the project by comparing the scope of works executed and the costs actually incurred against the project schedule and budget adopted in the base plan.

Compared to the traditional method of checking the project progress, the EVM method includes the third dimension: earned value, which represents the planned value of the scope of work actually executed, in the assessment of the condition of the project, in addition to planned and actually incurred costs. By developing this method, not only measurement possibilities and assessment of the actual results of operations based on the data found during control periods were obtained, but also analysis of performance trends and forecasts of the future cost of project activities and projections of the final project budget. Appropriate indicators allow at each stage of the implementation of works to assess the current status of the project and the possibility of its implementation within the planned budget and schedule. The indicators used in the EVM method can be calculated for both individual tasks and the entire project, as cumulative earned value $[9,10,11,12,13,14]$.

The basis of the earned value method is the Budgeted Cost of Work Performed (BCWP). It shows how much the work done as planned costs. If one wants to calculate it, they should have information on the planned cost of work to be incurred by the date of the inspection, and on the amount of work actually executed to that day. The essence of the earned value method is shown in Figure 1. The curve illustrating the course of BCWS - "Budgeted Cost of Work Scheduled" (planned costs) is determined during the project planning phase, its final value is BAC - "Budget at Completion" [15]. Curves illustrating the course of BCWP - "Budgeted Cost of Work Performed" (earned value) and ACWP - "Actual Cost of Work Planned" (costs incurred), are determined during the implementation of the works and can be determined only until the date of inspection.

The course of the curves in Fig. 1 also allows to see the variances from the budget and the schedule: both on the day of the inspection and forecast values on the day of completing the project. Data from the BCWS, BCWP, ACWP curves are the basis for calculating further indicators, to which in the EVM method belong: [8]

- Cost Variance (CV):

$$
C V=B C W P-A C W P
$$

- $\quad$ Schedule variance (SV):

$$
S V=B C W P-B C W S
$$

where:

BCWS - planned cost of the planned work until the day of inspection of the quantity of work of a given task,

ACWP - actual cost of the work executed up to the date of inspection of the quantity of work of a given task,

BCWP - the planned cost of the work executed to the day of work inspection of this task; value checking how much, according to plan, was paid for the work actually executed.

In the study [16], searching for reasons for delayed projects, monotonicity analyzes of the indicator corresponding to these assumptions were carried out, proposing the variance parameter from booked expenditure (AV: Accounting Spending Variance).

This indicator is described in the form:

$$
A V=C V-S V
$$




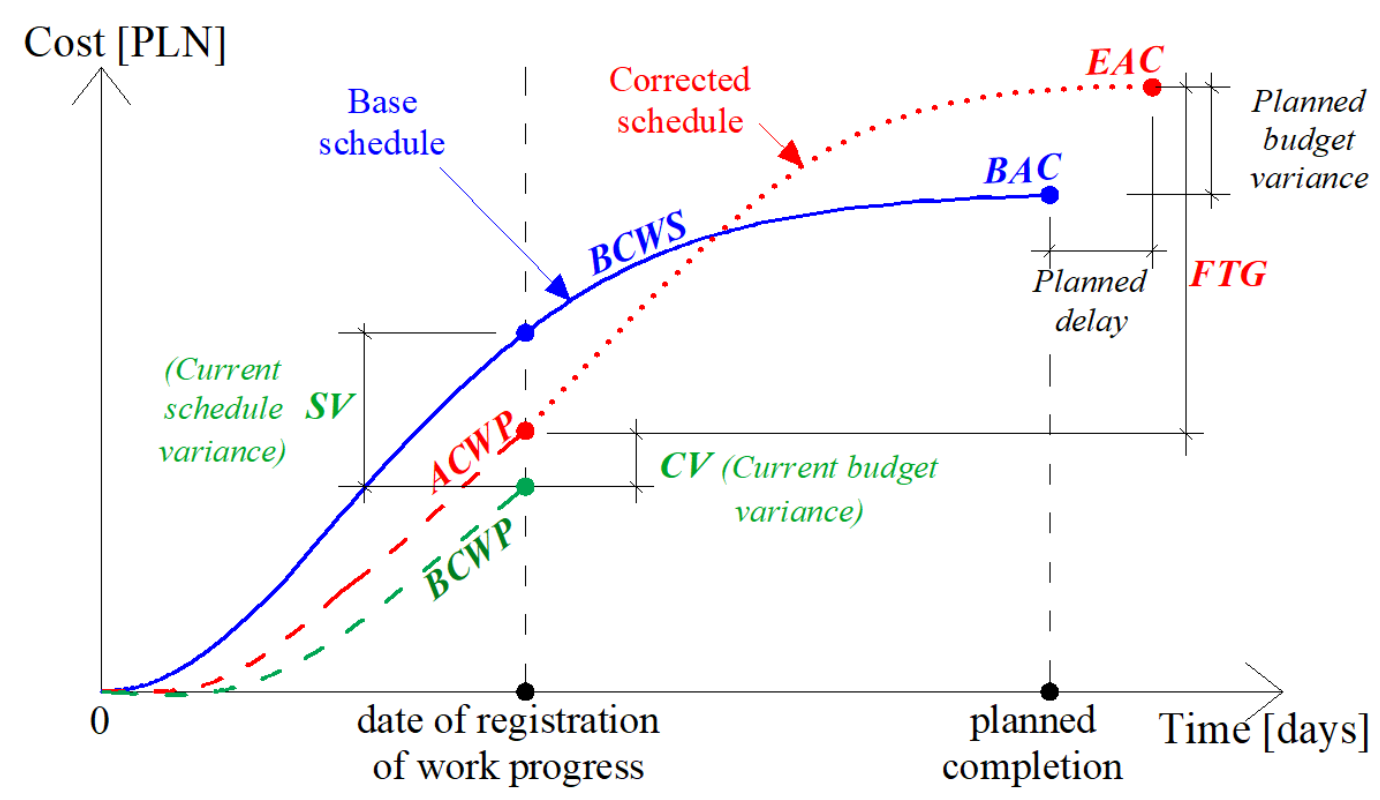

Figure 1. Elements of EVM method (description in text). Source: [17]

Thus, we have:

$$
\begin{aligned}
A V & =(B C W P-A C W P)-(B C W P-B C W S)= \\
& =B C W P-A C W P-B C W P+B C W S=B C W S-A C W P
\end{aligned}
$$

The proposed AV parameter monitors financial liquidity, which is the difference between planned and actually incurred costs. In this concept, commonly known as cost management, workflow is defined as "data and material movement" through the network of production units.

Current control systems, including EVM, focus on analyzing the "speed" of cost and time increases, ignoring the problem of the flow of production resources, in which the authors see major failures in their implementation processes. These systems are an effective control tool, but they have one serious limitation, treating each schedule process as an independent activity, the effect of which does not translate into the implementation of subsequent processes. In order to demonstrate positive increases in cost variances (CVs), managers strive to level production costs (ACWP) at the expense of continuous increase in process efficiency, which causes unreliability of workflow streams [18]. The conclusion of the study stated that, further research is necessary to develop alternative systems to monitor the progress of projects. A detailed analysis of the time variance of the schedule was undertaken in the study $[19,20,21]$, proposing a new look at the EVM method, marked as ES (Earned Schedule).

The basic assumption is a comparative analysis of the earned value ratio BCWP and the planned costs BCWS. The algorithm results are the values of time variances at individual moments of the project $(\mathrm{t})$, reflecting the periods in which the equality was to take place: BCWP $=\mathrm{BCWS}$, determined with the indicator of the earned schedule value (ES). This indicator is calculated as follows:

$$
S V(t)=E S-A T
$$

A graphic interpretation of the simple parameters of the ES method is shown in figure 2.

In turn, in the study [22], the EVM analysis was extended to include 'qualitative' indicators, proposing a qualitative technique in this method - (QEV: Quality Earned Value). 


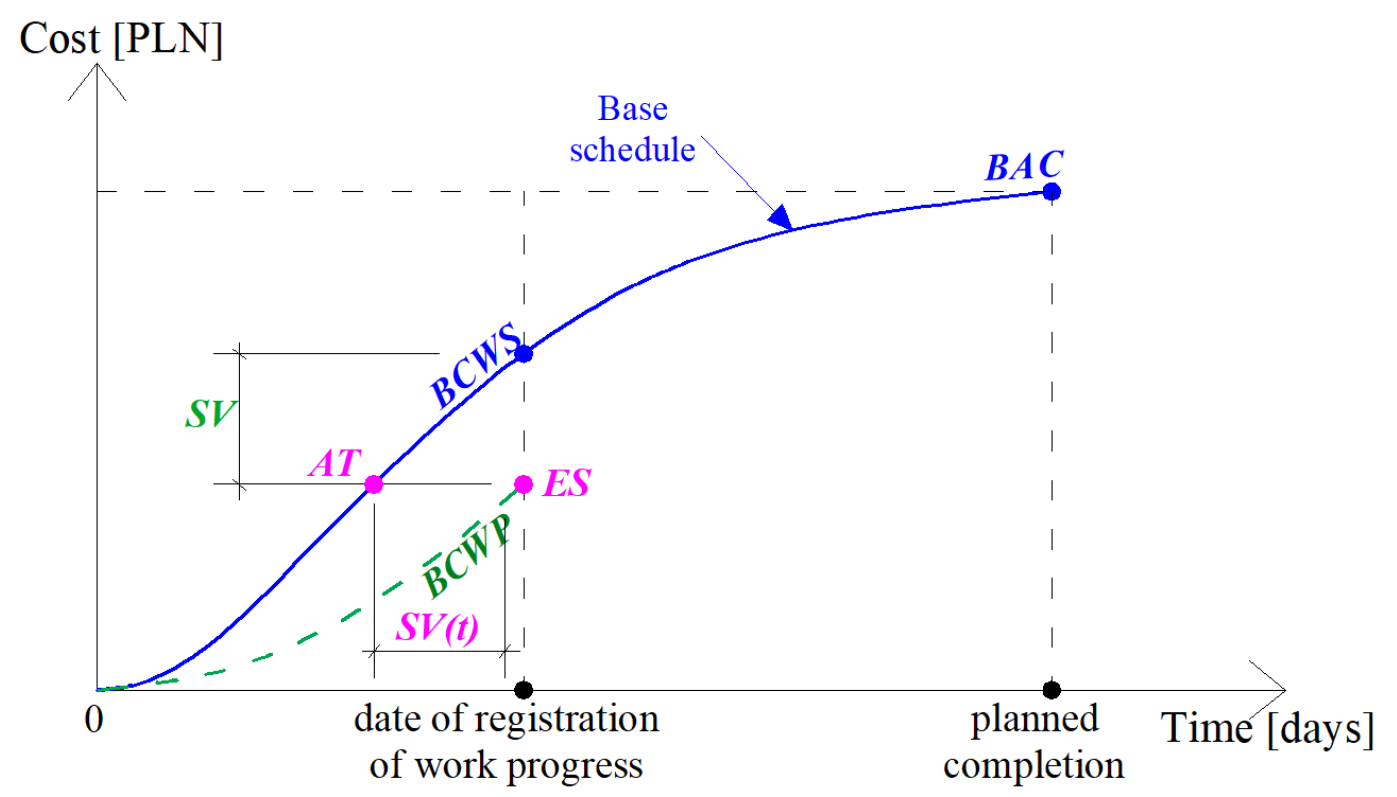

Figure 2. Graphic interpretation of simple parameters of the ES method (description in the text). Source: [17]

For this purpose, quality assessment parameters (QR: Quality Requirements) have been introduced. The methodology for calculating the QEV assumes formulas for assessing the quality of its components. Its purpose is to measure the project's ability to provide the assumed qualitative levels of the indicated tasks of the examined schedule. An additional research objective was an attempt to link the quality management process with monitoring of works progress.

Data was collected on the day each schedule task was completed. The results prove that, taking into account the parameter of assumed quality levels reduces the projected earned value of the project.

In the study [15], in order to increase the accuracy of early forecasting of the Estimated At Completion (EAC) project cost of the EVM method, its analysis was extended with the introduction of an innovative parameter of estimation of non-linear final cost regression (CEAC: nonlinear Cost Estimate at Completion). The methodology introduces the concept of "interim schedule" (ES: Earned Schedule) and ensures that, the CEAC indicator is determined at each stage of project implementation. In the course of the algorithm implementation tests, the equations of time and cost models (logistic, Gompertz, Bass, Weibull) are built, followed by the selection of one that best describes the implementation of the project, which is determined by the CEAC level.

The proposed methodology allows to determine in a more realistic way the parameter sought for the final cost of the project, by creating a wider field of analysis taking into account extensive mathematical models.

Another approach to expanding EVM analysis is the method of time-cost analysis described in the study [23], assessing the progress of works based on three additional assessment parameters: Early Start Rate (ESR), Early Completion Rate (ECR) and Cost Overrun Rate (COR).

These studies show that, the same orders, which are characterized with for example the purpose of the object, have an impact on their delivery time. A different approach to production monitoring has been proposed in the study [24] in the EDM (Earned Duration Management) method.

The role of this technique is to replace one of the tools of the EVM method, the schedule performance index (SPI) with its own EDI (Earned Duration Index) index in the form of an exponential function with a time argument. It has been shown that, this parameter gives more accurate results in comparison with the SPI. In addition to the purely informational model identifying the variances, the study also contains a method of solving the problem of their leveling, which can also be found in the study [25]. 


\section{Materials and Methods: description of the scheduled examined}

On the basis of simple indicators of the EVM method, a developed time-cost analysis is proposed [17], examining the impact of the project implementation time on the costs incurred and costs on the planned time - by introducing the following assessment parameters:

- Indicator for monitoring changes in the assumed financial liquidity due to arising time variances from the schedule $(\mathrm{T} / \mathrm{S})$ :

$$
T / S=\frac{T V}{S V}=\frac{B C W S-A C W P}{B C W P-B C W S}
$$

- Indicator for monitoring changes in assumed financial liquidity due to arising variances from planned costs $(\mathrm{T} / \mathrm{C})$ :

$$
T / C=\frac{T V}{C V}=\frac{B C W S-A C W P}{B C W P-A C W P}
$$

Their role is to expand the analysis with control indicators to analyze financial liquidity, by taking into account the costs and time variances in the schedule. Formula (6) extends the simple analysis of project liquidity by including the difference of the earned value indicator, corrected by the value of planned costs (BCWS), constituting its budget. In formula (7), a simple analysis of financial liquidity (difference in the value of planned BCWS costs and costs incurred ACWP) has been expanded to include the planned cost of the actual work done (BCWP earned value index), reduced by the actual cost (ACWP).

In the mathematical structure of indicators, it is unacceptable to equate the values of the BCWS, ACWP and BCWP parameters - at which the equality of the described tools indicate the implementation of works in accordance with the assumed time and cost. These cases do not require taking remedial actions to improve the monitored schedule. The following tests were performed to calculate the assessment parameters entered for the work schedule model, assuming three basic implementation structures - steady, parallel and sequence execution methods.

To carry out the analysis of time and cost variances, the schedule of the implemented construction project, consisting of the construction of a multi-family housing development, planned for a period of seven months, with a budget of over PLN 20 million, was used.

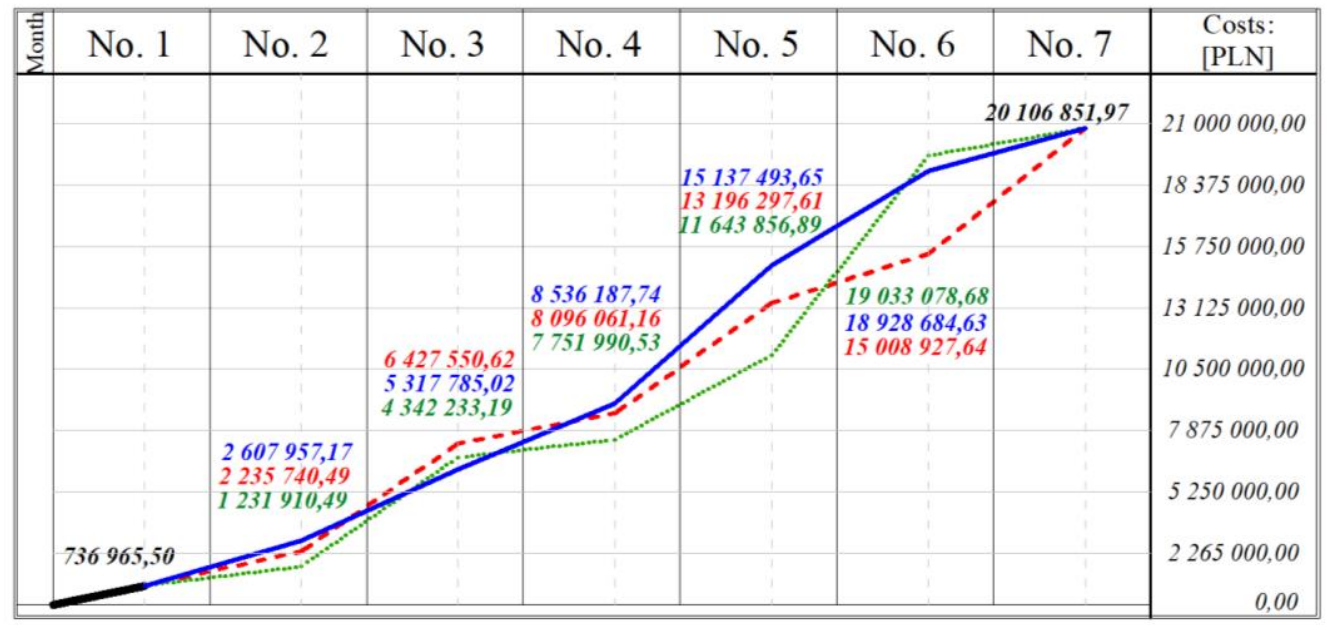

Figure 3. Cumulative values of planned costs (BCWS) of schedules - in implementation methods according to: steady (dot chart), parallel (continuous chart), sequence (intermittent chart) execution of works. Source: [17]

Figure 3 shows the obtained three scenarios for the implementation of works. 
The allocation of the means of production was planned using three basic structures of project implementation - methods of steady, parallel and sequence execution.

\section{Results: application of $\mathrm{T} / \mathrm{S}$ and $\mathrm{T} / \mathrm{C}$ monitoring}

$\mathrm{T} / \mathrm{S}$ and $\mathrm{T} / \mathrm{C}$ monitoring of variances arising during the implementation of the works covered by the schedule, was divided into three scenarios of its implementation, according to the methods adopted above. The adopted calculation models are characterized by a $10 \%$ increase in the budget of costs $(\mathrm{C}=110 \%, 120 \%, 130 \%, 140 \%)$ and a $5 \%$ increase in the time of works execution $(\mathrm{S}=105 \%$, $110 \%, 115 \%, 120 \%$ ), respectively. These models are described with symbols A1B1 $\div$ A4B4, indicating the increase in variances [8]. For T/S monitoring, the impact of the increasing delay parameter (A models) was adopted, while for $\mathrm{T} / \mathrm{C}$ monitoring the impact of delays and cost overruns combined (AB models).

The steady execution method assumes a global (overall) impact of variances (A, B) - for all schedule processes. In the methods of parallel and sequence work execution, the local (partial) impact of variances $(a, b)$ was adopted - on selected process sequences.

This is due to the obvious characteristics of these methods, widely described in the literature (delays of the analyzed process sequences do not always affect the delays of their successors).

Table 1. Schedule models according to the method of parallel execution. Source: [17]

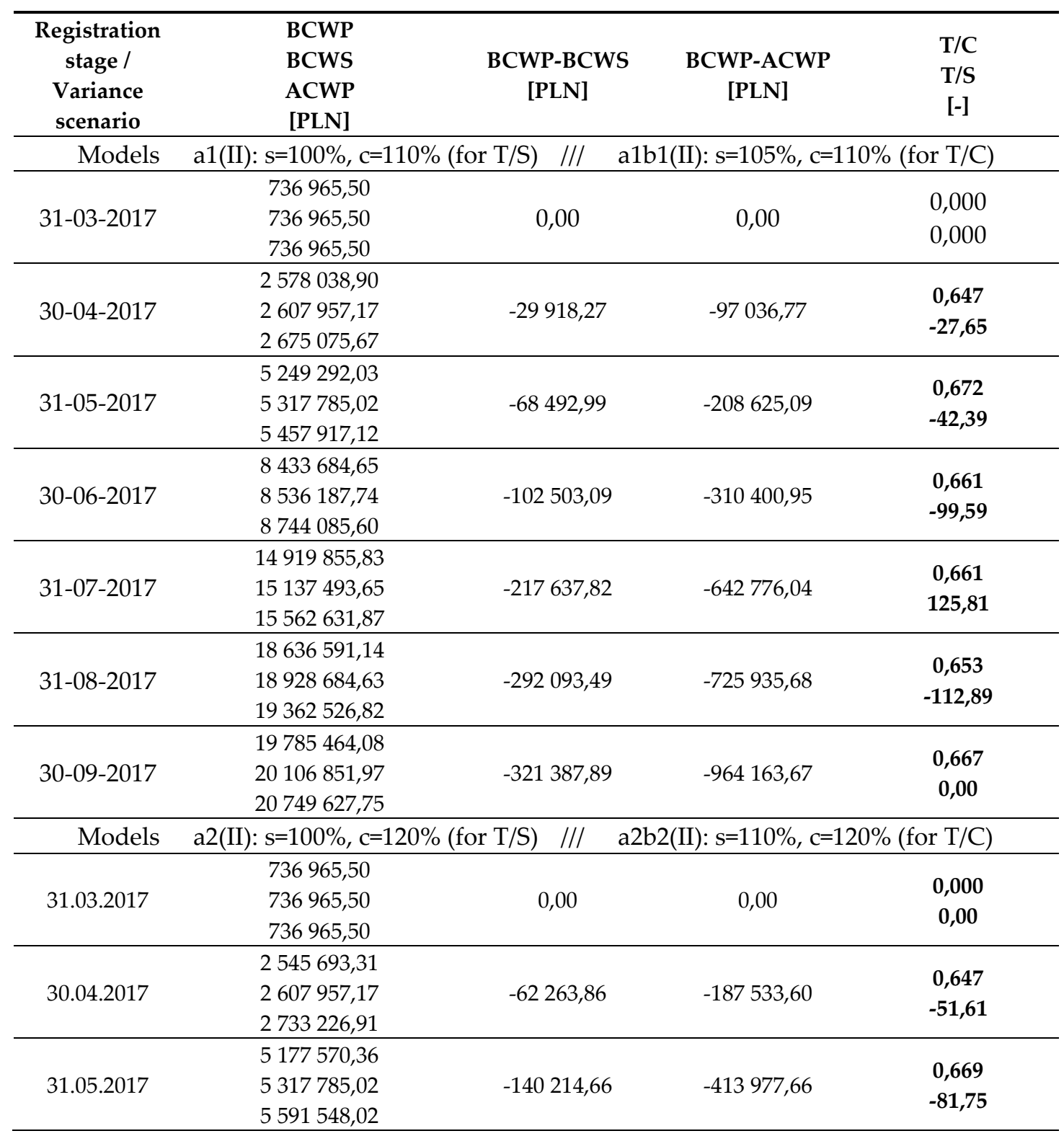




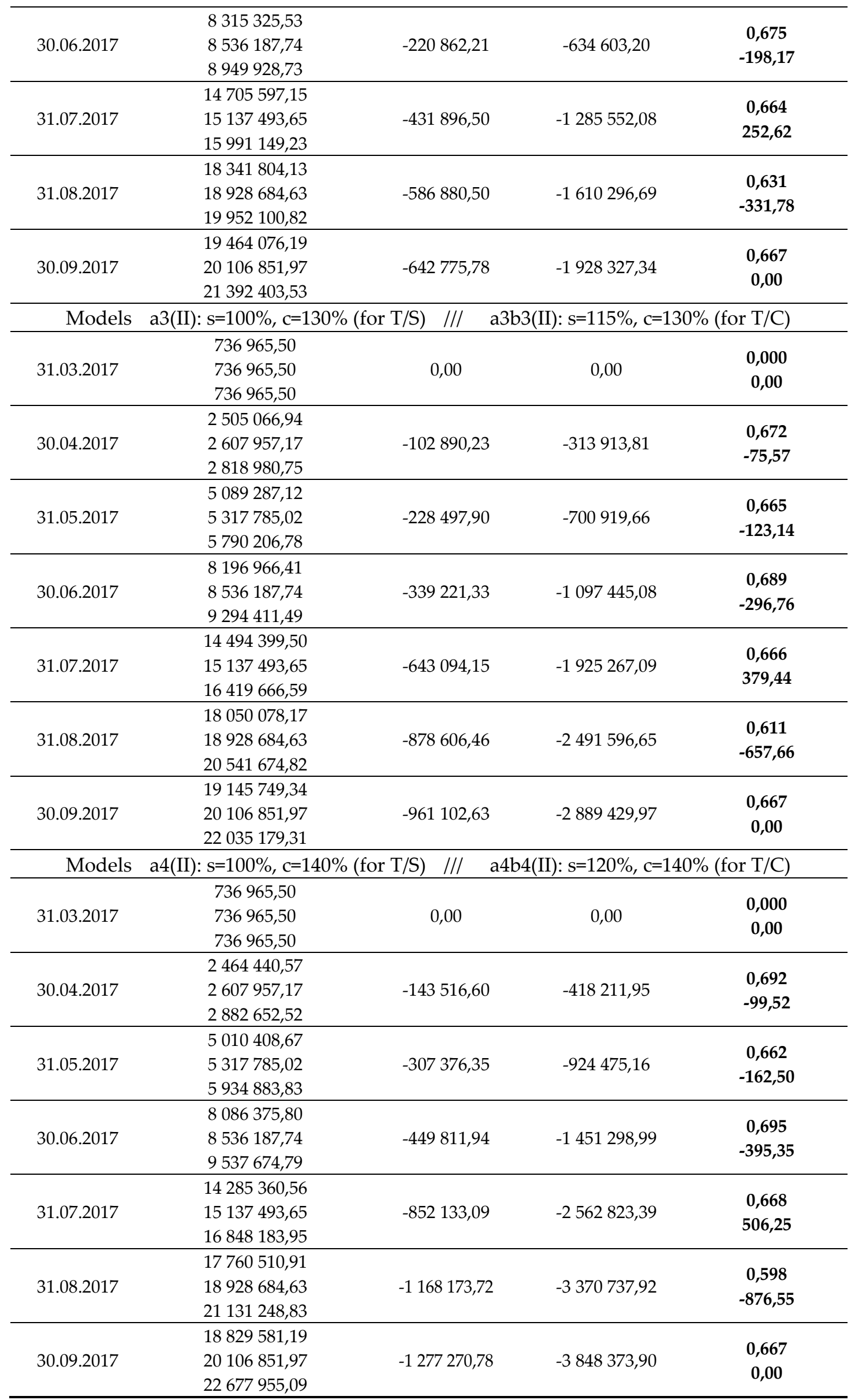


The analysis of the growth rate of unplanned costs and the work performance deviating from the plan consists in a gradual increase in expenditure on production (C), with a simultaneous systematic reduction of the production rate (S). These phenomena are reflected in the lowering of the value of simple indicators of the earned value method: pool of actual costs (ACWP) and earned value index (BCWP), which determine the monotonicity of the $\mathrm{T} / \mathrm{S}$ and $\mathrm{T} / \mathrm{C}$ monitoring indicators.

The results of the analysis for the parallel execution method, with a description of the introduced time and cost disturbances and the division into four variances scenarios, are presented in Table 1.

Similar calculations were carried out for the steady execution method and the sequence work execution. The picture of emerging disturbances is presented in figure 4 (monitoring of variances from the assumed time T/S) and No. 5 (monitoring of variances from the assumed costs T/C).

Monitoring of variances from the assumed duration (T/S) in the schedule planned according to the assumptions of the steady execution method shows the highest values in the fifth control stage.

At this stage, the highest production throughput occurs, reaching $15 \%$ of the total costs (Fig. 3 ).

The highest T/S values were recorded in this group of scenarios, which results from cumulative variances related to the production stream of works.

Monitoring (T/S) in the schedule made according to the assumptions of the parallel performance method shows a typical increase in the analyzed values, together with the increase of the stimulus value, in subsequent scenarios. The highest positive $\mathrm{T} / \mathrm{S}$ monitoring values were also obtained for the fifth stage, in which activities with the largest budget were carried out. During the sixth inspection period, the lowest negative variance levels were recorded to the assumed time, illustrating the losses of the previous, fifth stage.

Monitoring of time variance of the schedule (T/S) in the sequence execution method - subject to the influence of local, gradually increasing disturbances, illustrates the planned course of works until the end of the third month. Then the amplitude of fluctuations in the results reflects the modeled disturbances: twice changing the sign - as in the case of the parallel execution method, although in this case the T/S tool recorded jumps of these values five and ten times higher.

It results from the specifics and assumptions of the analyzed implementation structure of projects. In all cases, the assumed methods of implementation accepted within them, four scenarios of gradual increase in variances illustrate rational, systematic increases in value, demonstrating the proper operation of the tested computational procedure of T/S monitoring (fig. 4).

In the statement of the second and third stage of registration of works in the schedules planned with the methods of parallel and sequence execution, a clear $\mathrm{T} / \mathrm{S}$ response to previously modeled variances in the structure of parallel execution of works can be seen.

Monitoring of varainces from the assumed costs of the project $(\mathrm{T} / \mathrm{C})$ in the steady execution method illustrates, unlike the other two methods, values greater than zero at all stages of recording the progress of works. This is due to the global nature of modeled time and cost distortions in this method. Similar to T/S monitoring, the largest value amplitudes were noted in the fifth and the sixth stage of registration, in which works with the highest budgets were executed.

The monitoring of cost variances $(\mathrm{T} / \mathrm{C})$ in the method of parallel execution records a zero value in the first stage of registration, in which no interference occurs. Then, the $\mathrm{T} / \mathrm{C}$ monitoring values remain at $60 \% \div 70 \%$ until the end of the project - the disturbances do not accumulate. Contrary to the above conclusion, in the next method - the sequence execution, T/C monitoring presents overlapping losses in sequence recording stages (resulting from modeled disturbances), starting from the fourth control stage. It results from the basic assumption of this method, in which the time delays of the analyzed sequence of processes affect the delays of its successors. In the first three stages of registration, T/C monitoring records zero values because no distortions were modeled in them.

As in the case of T/S monitoring, the definition of four scenarios of gradual increase in interference gives the systematic monotonicity of the graphs of their functions in the project implementation calendar, in each of the structures analyzed (fig. 5). 


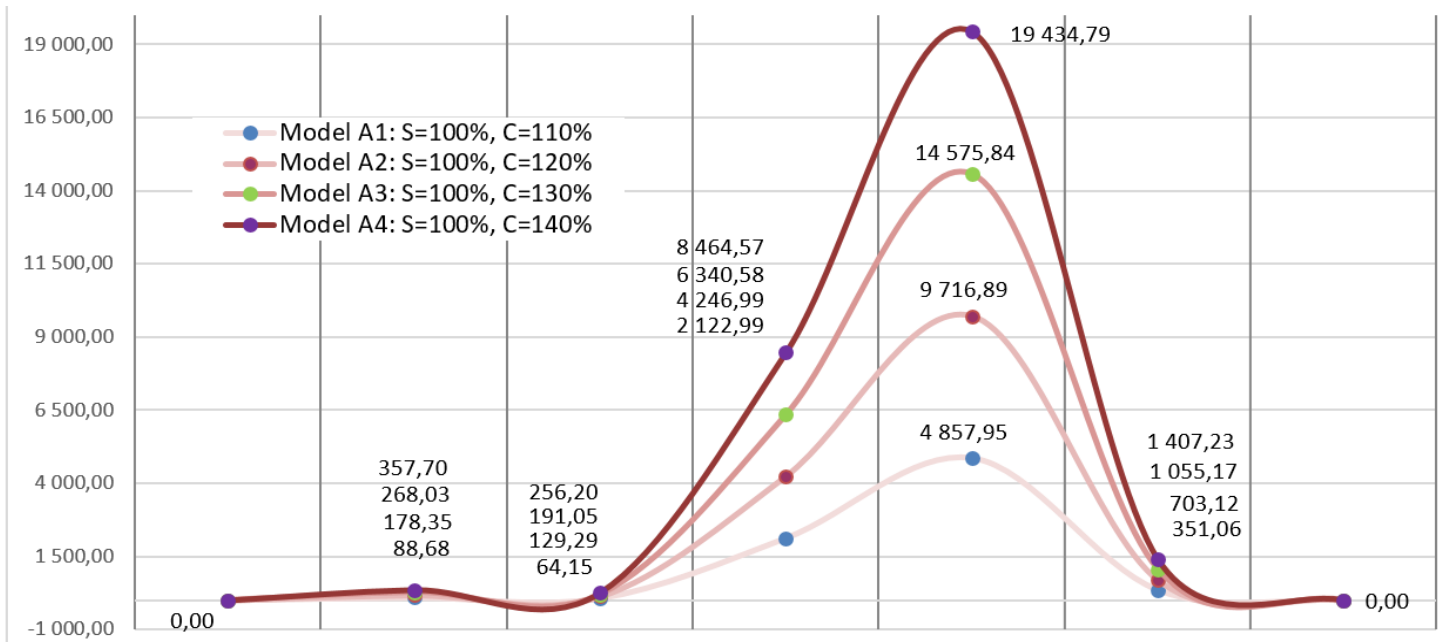
01.03 .2017
01.04.2017
01.05.2017
01.06.2017
01.07.2017
01.08.2017
01.09.2017
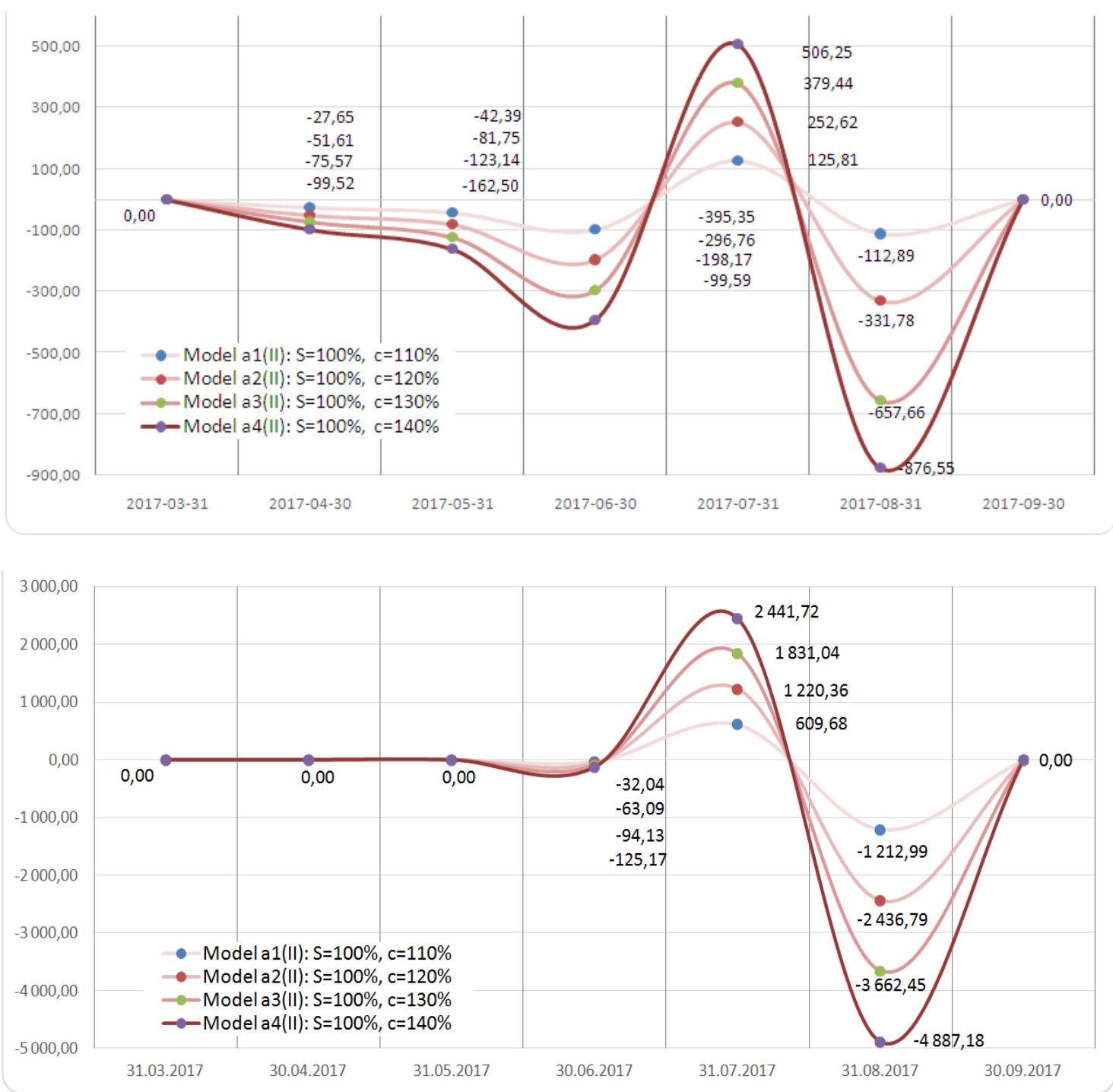

Figure 4. Monitoring indicator charts in the assumed financial liquidity due to the occurring time variances from the schedule $(\mathrm{T} / \mathrm{S})$ in models with a gradually increasing time variance in the implementation methods according to (from above): steady, parallel, sequence execution of works. Source: [17] 

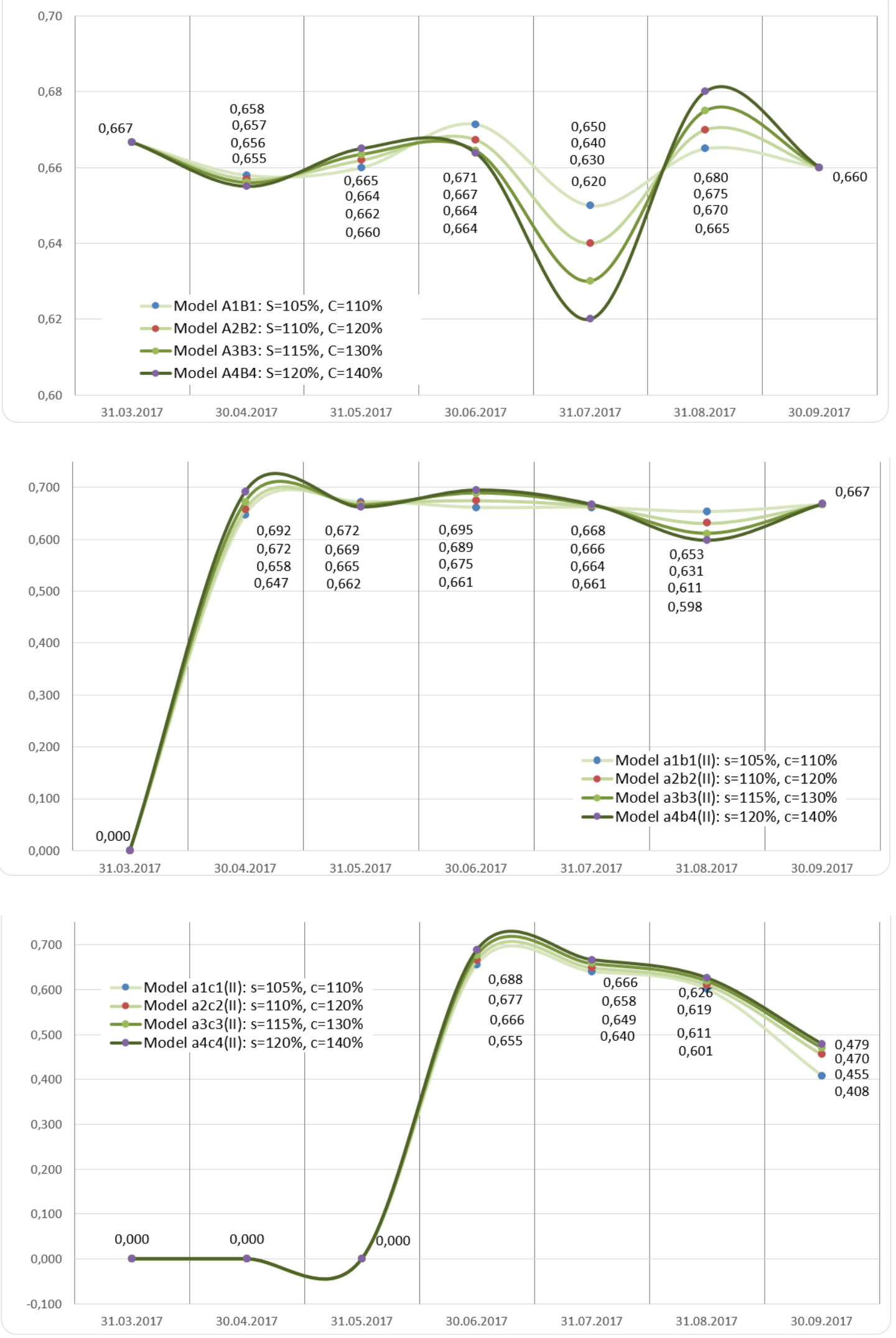

Figure 5. Monitoring indicator charts in the assumed financial liquidity due to arising variances from planned costs $(\mathrm{T} / \mathrm{C})$ in models with a gradually increasing time and cost variance in the implementation methods according to (from above): steady, parallel, sequence execution of works. Source: [17] 


\section{Conclusions}

The role of additional tools of the EVM method - T/S and T/C monitoring is to take into account the financial liquidity of the project in the analysis of time and cost variances of the assumed schedule. These tools are an important complement to the workshop of the earned value method, fully compatible with its simple indicators.

Under the influence of the budget's underestimation and time slips, the planned cost and time distribution changes, expressed in the course of the financial liquidity (TV) parameter. Planned cost parameter (BCWS),depending on the situation in the project monitoring, should therefore be flexible - already at the budgeting stage.

In the case of modeling total (global) time and cost variances, the largest values from the T/S and T/C monitoring calculations were recorded for periods containing the "longest" and "most expensive" schedule activities. Subjecting the schedule to partial (local) time and cost variances eliminated these values - while maintaining the proportion of their results - in relation to total (global) distortions.

In practice of management of long-term construction projects, these tools may contribute to the identification of variances from the assumed schedules, describing - in contrast to the classical EVM method - their actual values.

\section{References}

1. Czyżewski A., Economic analysis in the implementation of investment projects. Poznań: Publishing house of the Poznań University of Economics, 2011.

2. Project Management Institute. A Guide to the Project Management Body of Knowledge (PMBOK GUIDE), 6th ed.; Project Management Institute (PMI): Newtown Square, PA, USA, 2017. [Google Scholar].

3. Połoński, M. Management of Construction Investment Process; Wydawnictwo SGGW (in Polish): Warszawa, Poland, 2018. [Google Scholar].

4. Al-Jibouri, S.H. Monitoring systems and their effectiveness for project cost control in construction. Int. J. Proj. Manag. 2003, 21, 145-154. [Google Scholar] [CrossRef].

5. Lo, W.; Chen, Y.-T. Optimization of Contractor's S-Curve. In Proceedings of the 24th International Symposium on Automation \& Robotics in Construction (ISARC 2007), 19-21 September 2007; pp. 417-420. Available online: https://www.irbnet.de/daten/iconda/CIB11259.pdf (accessed on 18 March 2020).

6. Hsieh, T.-Y.; Hsiao-Lung Wang, M.; Chen, C.-W. A Case Study of S-Curve Regression Method to Project Control of Construction Management via T-S Fuzzy Model. J. Mar. Sci. Technol. 2004, 12, 209-216. [Google Scholar].

7. Chen, H.L.; Chen, W.T.; Lin, Y.L. Earned value project management: Improving the predictive power of planned value. Int. J. Proj. Manag. 2016, 34, 22-29. [Google Scholar] [CrossRef]

8. Trocki M., Modern project management. Warsaw: P.W.E., 2012.

9. Dziadosz, A.; Kapliński, O.; Rejment, M. Usefulness and fields of the application of the Earned Value Management in the implementation of construction projects. Bud. Archit. 2014, 13, 357-364. [Google Scholar].

10. Waris, M.; Khamidi, M.F.; Idrus, A. The Cost Monitoring of Construction Projects through Earned Value Analysis. J. Constr. Eng. Proj. Manag. 2012, 2, 42-45. [Google Scholar] [CrossRef].

11. Bhosekar, S.K.; Vyas, G. Cost Controlling Using Earned Value Analysis in Construction Industries. Int. J. Eng. Innov. Tech. 2012, 1, 324-332. [Google Scholar].

12. Vandevoorde, S.; Vanhoucke, M. A comparison of different project duration forecasting methods using earned value metrics. Int. J. Proj. Manag. 2006, 24, 289-302. [Google Scholar] [CrossRef].

13. Howes, R. Improving the performance of Earned Value Analysis as a construction project management tool. Eng. Constr. Archit. Manag. 2000, 7, 399-411. [Google Scholar] [CrossRef].

14. Czemplik, A. Application of earned value method to progress control of construction projects. Procedia Eng. 2014, 91, 424-428. [Google Scholar] [CrossRef].

15. Narbaev T., De Marco A., Combination of growth model and earned schedule to forecast project cost at completion method. Journal of Construction Engineering and Management, 2014, v.140 Issue 1.

16. Kim Y., Ballard G., Is the earned-value method an enemy of work flow? Eighth Annual Conference of the International Group for Lean Construction (ILGC-8) Proceedings IGLC-8, 2000, p. 142-144.

17. 5Przywara D., Time-cost analysis in monitoring the works of the construction schedule. Dissertation. Opole University of Technology, Opole, 2019.

18. Maravas, A.; Pantouvakis, J.-P. Project cash flow analysis in the presence of uncertainty in activity duration and cost. Int. J. Proj. Manag. 2012, 30, 374-384. [Google Scholar] [CrossRef]. 
19. De Koning P., Vanhoucke M., Stability of earned value management: Do project characteristics influence the stability moment of the cost and schedule performance index. Journal of Modern Project Management, 2016, $4(1)$, p. 8-25.

20. Vanhoucke M., Vereecke A., Gemmel P., The project scheduling game (PSG): simulating time/cost trade-offs in projects. Project Management Journal, 2005, v. 36(1), p. 51-59.

21. Przywara D., Rak A., Analysis of time-cost of monitoring schedule by Earned Value Method. Technical Journal, 2017, Volume 2-B(6),p. 41-50.

22. Dodson M., Defavari G., De Carvahlo V., Quality: the third element of Earned Value Management. Procedia Computer Science, 2015, v. 64, p. 932-939.

23. Chen Q., Jin Z., Xia B., Skitmore M., Time and cost performance of design build projects. Journal of Construction Engineering and Management, 2016, ASCE, 142(2), p. 162-169.

24. Khamooshi H., Abdi A., Project duration forecasting using Earned duration management with exponential Smoothing techniques. Journal of Management in Engineering, 2017, v.33 Issue 1.

25. Przywara D., Rak A., Modeling of optimal timing transition of front production by the two-punctual network note schedule. Open Journal of Architectural Design, 2014, v.2(1), p. 1-5. 